COMMENT

Received 7 Apr 2017 | Accepted 30 May 2017 | Published 4 Jul 2017

DOI: $10.1057 /$ palcomms.2017.61

\title{
Ordinary religious experience, learning and adaptation: a call for interdisciplinary inquiry
}

Nathaniel F. Barrett ${ }^{1}$

ABSTRACT Within disciplines of religious studies, discussions of religious experience tend to revolve around the most rare and extraordinary cases, while neglecting much more common varieties of "ordinary religious experience"-that is, experiences of regular practitioners in the midst of normal religious activities such as worship or prayer. This comment will, first, call attention to this essential aspect of religious life, and, second, will suggest ways in which it can be made more accessible to investigation. This article suggests that researchers focus on the variability of engagement in religious practice and the processes of learning and adaptation by which regular practitioners enhance their experience of religious practice. It also suggests that ethnographic studies be extended by carefully selected theories of perception and cognition that address the role of material conditions in ordinary religious experience. 


\section{The importance of ordinary religious experience}

W hen taking up religious experience as an object of study, the tendency of scholars has been to focus on the most extraordinary varieties: sudden, rare and fleeting, but powerful experiences such as mystical and conversion experiences-experiences that, as a rule, no one can learn to have. Even critiques of religious experience (for example, Sharf, 1998; Martin and McCutcheon, 2012) have tended to reinforce this narrow view of what it includes. Meanwhile, comparatively little attention has been paid to common varieties of what might be called "ordinary religious experience", especially the kind that can be learned through regular religious practice. My purpose in this article is to bring this important but neglected aspect of religious life into focus, highlight some of its key observable features and indicate its potential interest as an object of interdisciplinary investigation.

To begin, let us understand "ordinary religious experience" as encompassing all experiences of regular practitioners in the midst of overtly religious activities, including everything from Amish baptisms to Zoroastrian hymns. "Experience" is to be used here in a broad, commonsense, naturalistic and non-judgmental way: nothing should be presumed about the special objects of religious experiences (that is, supernatural beings or ultimate realities); they should not be marked off by any special sensory dimension or epistemic status; and questions of veridicality and authenticity should not enter into consideration. Insofar as it is possible to identify regular religious practitioners (for example, practicing Jews) engaged in overtly religious activities (for example, the festival of Sukkot), we are interested in any and all experiences that are had during this engagement.

Granted, such an overwhelming diversity of experiences can be found in this category that it becomes nearly unmanageable as an object of study. But not everything that fits into this category is likely to be of equal interest. For example, perhaps one of the most common religious experiences, and certainly one of the most ordinary, is boredom-hardly the kind of experience that invites serious study. But while the boredom of religious practitioners may not tell us much in itself, it points to an extremely important feature of ordinary religious experience that can serve as a crucial entry point of investigation: variability of engagement. Just as there are lots of kinds of ordinary religious experience, there are lots of kinds and degrees of religious engagement. Here, I wish to direct attention to variability of engagement as indicated by the subjectively experienced meaning and value of religious activities.

Although the variability of engagement can be difficult to observe from the outside, it is reasonable to assume that religious practitioners are more or less aware of it. Especially in experientially oriented activities, practitioners frequently monitor their level of engagement: "Today I was really into it" or "Today I wasn't really into it". Such feelings mark an important distinction between engagement and participation: a regular practitioner can participate in an elaborate religious ritual all the while thinking about something else. Disengaged religious participation can take many forms-it includes boredom, doziness and distraction, as well as just "going through the motions"-all of which can be lumped together as a broad, baseline level of ordinary religious experience.

The reason for highlighting this baseline is that it helps us to appreciate the many subtle variations of engagement and enjoyment that characterize ordinary religious experience. Between total disengagement and mind-blowing religious ecstasy lies an enormous range! And yet this middle range is overlooked by discussions that focus only on the "peaks" of religious experience. Indeed, insofar as religious experience is conceived as something extraordinary that "just happens to you", level of engagement is simply assumed or irrelevant. Yet to disregard the variability of engagement that occurs within the middle range of religious experience between boredom and ecstasy is to miss the striving after meaning and value that animates the ordinary religious life.

Indeed, I suggest that the kinds of religious experience that fall within this middle range are the lifeblood of religiosity, and as such should be a primary focus of religious studies. The most obvious reason for this importance is the likelihood that the bulk of religious experience falls somewhere within this range. But another, perhaps deeper, reason is the fact that religious practitioners are often acutely aware of the variability of their own religious engagement and its frequently all-too middling quality, and this self-awareness constitutes an important dimension-perhaps even a central concern-of ordinary religious experience as it develops over time. If ordinary religious experience is the lifeblood of religiosity, the concern for increased religious engagement is its heart, the spring that drives it forward.

To say that a concern for engagement is the heart of religiosity does not mean that religious practitioners are always so concerned. Lack of concern for engagement may be fairly widespread, even among active practitioners. Nevertheless, I think it is uncontroversial to presume that religious culture is shaped in part by the desire of practitioners to experience their practice more meaningfully. ${ }^{1}$ Accordingly, a principal objective for religious scholars should be to describe and understand the processes by which this crucial process of "religious learning and adaptation" occurs. In the remainder of this article I wish to unpack some of the crucial elements or "interactants" of this process so as to indicate various pathways of enquiry.

\section{Measuring religious engagement}

First, to proceed along these lines, we need to develop and refine our ways of characterizing the subjective side of religious engagement within this middle range. Perhaps the lowest form of engagement is simply a state of mild attentiveness and interest. Continuing from there, we might find a wide variety of markers rather than a single scale, as religious engagement can take many forms. However, I suggest that it may be possible to understand increased religious engagement in general terms of perceptual discernment and emotional attunement, especially as directed towards whatever religious meanings and values are made materially present (for example, by objects, language, ritual behaviours, imagery, music and so on) within the context of a religious activity. Accordingly, the upper regions of the engagement scale (still within the middle range) might be characterized by skilled participation and full absorption, together with direct or "perceptualized" enjoyment of religious meaning (Barrett, 2014b). ${ }^{2}$

One of the advantages of focusing on this middle range of experience is that its central feature, variability of engagement, suggests that it can be made amenable to empirical study. Within this range, personal involvement varies over time within individual religious lives-even within the same activity-as well as across individuals, activities, settings, traditions and so forth. So, for example, if we were to conduct an extensive "experience sampling" study of religious engagement in a particular religious community (asking practitioners to report periodically on their level of engagement or quality of experience; see Larsen and Csikszentmihalyi, 1983), we would likely find lots of variation within whatever spectrum of engagement is defined by the study. And as we collected more and more experience samplings over time, we might find that the data points gave rise to definite shapes and patterns. What would those patterns tell us? And what further studies of ordinary religious experience would they open up? 
Once we have a fairly good sense of the variability of engagement within a particular religious tradition or community, our attention can turn to the processes by which more specific kinds of religious engagement are enhanced. And, as suggested above, such processes can be further broken down into processes of religious learning and adaptation. Let us take each of these in turn.

\section{Religious learning}

The critical importance of religious learning is indicated by the variability of engagement and experience just mentionedvariability between practitioners who belong to the same tradition or community, as well as within the practice of a single individual over time. Religious learning, as delineated here, includes everything relevant to the experiential enhancement of religious practice that can be acquired by practitioners: knowledge, skills, habits, sensitivities and so on. Religious learning can be directed and intentional (for example, bible study group, meditation class), or undirected and "osmotic" (for example, the experience of a child accompanying her grandmother to a Buddhist temple). The processes of religious learning that are most accessible to investigation are those that are explicitly defined as such. For example, glossolalia (speaking in tongues) is something that certain religious traditions encourage practitioners to learn, sometimes in a fairly deliberate way. How does this work? Who guides the process, how is progress defined and what kinds of skills are required?

More generally, questions pertinent to the study of religious learning include the following: What is involved in becoming a practiced practitioner? What distinguishes the religious expert from the novice, the engaged and fulfilled practitioner from the disengaged and unfulfilled? What techniques are used and what resources are required for the acquisition of skilful practice? What are the common pitfalls that hinder this process? How do practitioners understand the religious learning process and its goals, and how have different traditions understood this process historically? What kinds of methodologies and theoriesespecially cognitive theories-can help us to investigate and understand religious learning?

\section{Religious adaptation}

Another way to define religious learning in the context of regular practice is to say that it includes all the ways in which practitioners adapt themselves to a practice in pursuit of various experiential goals. But this is not the only adaption that occurs. As in many processes of evolution, religious adaptation is actually two-sided: over time, religious cultures are also adapted to the needs and desires of religious practitioners. Processes of religious adaption can be effected by self-conscious and deliberate choices, for instance in the careful selection of music for worship (see Porter, 2017). But they can also take place gradually through largely unconscious processes of cultural change and social selection. This socio-cultural side of religious adaption opens up another set of questions, which are separable but not entirely distinct from the questions of religious learning.

In general, questions of religious adaptation have to do with the way in which various material aspects of a religious practice are adapted to enhance the meaningful experience of that practice. Religious materiality is a complex sphere of growing scholarly interest (Meyer et al., 2010) that pertains to more than just religious objects (for example, reliquaries): it also encompasses bodies (for example, positions of salat or Islamic prayer), places and practices. In many cases, the way in which religious materials have been adapted to religious experience may be fairly easy to discern: for instance, positions of prostration are widely used to induce feelings of reverence, certain religious architectural styles evidently developed in part to express theological meanings, and religious music can be tailored to induce appropriate moods and so on. However, more comprehensive and rigorous investigations of the specifically experiential contribution of religious materiality may depend on the development of special theoretical and methodological approaches.

\section{A call for interdisciplinary enquiry}

Accordingly, in this section I wish briefly to indicate how the pursuit of these questions requires a distinctive orientation, as well as the cooperation of diverse disciplinary perspectives. No doubt questions like the ones just laid out have already been investigated by numerous scholars, and a substantial amount of knowledge about ordinary religious experience can be gleaned from a variety of sources. Yet to my knowledge there are few if any systematic treatments of these questions that can be used to guide and inform both scholarly and public discussion of ordinary religious experience. In general, my sense is that topics of religious engagement, learning and adaptation as discussed here have received comparatively attention, especially from those involved in the empirical study of religion. One reason, it seems, is that the specifically experiential dimension of regular religious practice and learning is difficult to subject to rigorous, empirical investigation. But another reason is that it has not been prioritized as an object of study.

Consider the study of prayer. In his introduction to a special section of empirical studies published in a recent volume of Research in the Social Scientific Study of Religion (2016), the psychologist Kevin Ladd notes that academic interest in the study of prayer "has been comparatively low" (p. 119). Moreover, within the existing literature, the scope of interest is limited in a way that mostly excludes the experience of prayer. This limitation is indicated by the collection introduced by Ladd (but see Aveyard, 2016), as well as his own comprehensive review of the psychology of prayer (Spilka and Ladd, 2012). It seems that the majority of studies have focused on measuring the frequency of prayer and the relationship between prayer and other indicators both religious and non-religious (worship attendance, health and so on), and when prayer practice itself is the object of study the focus has been primarily cognitive rather than experiential. Even with respect to the motivational dimension of prayer (ibid.: 29-30), what is conspicuously missing is any interest in prayer as an intrinsically motivated activity, which is to say the experienced value of prayer itself. This is precisely the dimension of prayer and other religious practices to which I am directing attention here.

Again, this lack of attention likely has a lot to do with the challenges presented by normal experience to objective, empirical study (compare with the study of musical experience, which faces similar challenges; see, for example, Juslin and Sloboda, 2010). In the face of these challenges, I suggest that ethnographic studies of religious practice can play a critical role in the development of new methods for the empirical study of religious experience. An especially relevant and noteworthy example is Tanya Luhrmann's study of charismatic Evangelical practice, When God Talks Back: Understanding the American Evangelical Relationship with God (2012). Luhrmann's main objective in undertaking this study was to answer the question, "How does God become real for people?". This is an experientially directed question, and her answer is a detailed account of a culturally specific process of religious learning. In her construction of this account, Luhrmann makes heavy use of psychological concepts, which one reviewer has criticized as a possible weakness of her approach (Jenkins, 2013). Yet I would argue that such theoretical extensions of ethnography are precisely the kinds of interdisciplinary innovations that are required if we are to make progress on the questions laid out 
above. As I have detailed elsewhere (Barrett, 2014a), Luhrmann's account of religious learning in an American Evangelical context involves a fairly subtle position on the nature of perceptual learning (that is, as a process of differentiation), and this, I believe, is a theoretical advantage, not a liability, as it suggests a number of testable implications for other kinds of perceptual learning, both religious and non-religious.

Moreover, I would argue that the view that the experience of religious practitioners is too elusive to be the object of study itself assumes a particular psychological theory of experience as an entirely private affair, "inside the head", whose subjective report cannot be checked against anything publically verifiable. There are no psychologically innocent approaches to the study of religionincluding those that give experience a wide berth-thus perhaps the better path is to confront experience as directly as possible and correct for inevitable biases and blind spots by drawing from multiple disciplinary and theoretical perspectives.

In particular, how we understand the role of religious materiality in experience depends implicitly on our theories of perception and cognition (Barrett, 2014a). As mentioned above, in many cases it is difficult to describe how a religious culture has been adapted specifically to the production of religiously meaningful experience. Yet the mere possibility that such adaptation has occurred will be missed entirely if we presume that experience is something constructed within the head rather than an "ecological" phenomenon, that is, a process that depends on dynamic relations between structures in and outside the body. Thus, for example, our attempts at objective description of the physical objects used in a religious ritual can differ in significant ways depending on our theoretical assumptions about how objects, bodies and ambient light interact to produce visual experience (cf. Marr, 1982; Gibson, 1986). Likewise, our sense of what is relevant for an ethnographic study of religious music depends on theoretical assumptions about the perception of musical meaning (for example, Clark, 2005). In summary, although the descriptive detail of ethnography may be a necessary basis for the study of ordinary religious experience, to investigate and understand processes of religious leaning and adaptation this detail needs to be extended by carefully selected theories of cognition and perception.

\section{Does the material exclude the spiritual?}

Finally, in closing, I would like to address two potential objections to the study of ordinary religious experience as outlined here. First, because I am directing attention to experiences of the inherent meaning and value of religious practice, it could be objected that this orientation is apologetic in nature. But seeking to understand how a religious practice is experienced as meaningful and valuable does not necessarily entail any desire to demonstrate its absolute or universal value. On the other hand, because my intent is to promote naturalistic ways of understanding ordinary religious experience, it could be objected that this approach necessarily discounts religious (that is, theological) interpretations of the special value of religious practice.

In reply to this last objection, I would point out that various naturalistic and theological interpretations of religious experience can and do peacefully coexist within religious practice. Indeed, it seems that practitioners often have fairly complex notions of the interplay of "sacred and profane" in their enjoyment of a religious practice, such that one rarely if ever dominates in a way that excludes the other. For example, a Christian evangelical likely believes that the presence of the Holy Spirit does not depend on the quality of worship music, but that does not mean that she is indifferent to how well this music is played. I do not mean to claim that there no tensions or inconsistencies hiding within practitioners' concepts of religious engagement and experience, just that the issue is complicated, and that investigations of the material conditions of ordinary religious experience need not be pursued in a way that resolutely excludes the spiritual meaning and value of practice.

\section{Notes}

1 On the other hand, I do not want to exaggerate this tendency in a way that leans towards specifically Protestant notions of the importance of experience. What is claimed here is a general desire for meaningful experience, not an aspiration to strong experiential justifications of religious belief.

2 "Enjoyment" needs careful qualification, as the kind of experiential enhancement of religious practice to which I am referring should also apply to funerals and other practices that for obvious reasons are not meant to be literally enjoyed. I am not sure what word would serve better in these cases.

\section{References}

Barrett NF (2014a) The perception of religious meaning and value: An ecological approach. Religion, Brain \& Behavior; 4 (2): 127-146.

Barrett NF (2014b) Perceptualization and the enjoyment of religious practice: A Response to Commentators. Religion, Brain \& Behavior; 4 (2): 171-180.

Aveyard M (2016) How young adult Middle Eastern Muslims interpret various prayer positions in Salat. In: Village A and Hood Jr RW (eds). Research in the Social Scientific Study of Religion. Brill: Leiden, the Netherlands, pp 158-173.

Clark E (2005) Ways of Listening: An Ecological Approach to the Perception of Musical Meaning. Oxford University Press: Oxford.

Gibson JJ (1986) The Ecological Approach to Visual Perception. Routledge: New York.

Jenkins T (2013) "Religious experience" and the contribution of theology in Tanya Luhrmann's When God Talks Back. Journal of Ethnographic Theory; 3 (3): 369-373.

Juslin PN and Sloboda JA (eds) (2010) Handbook of Music and Emotion: Theory, Research, Applications. Oxford University Press: Oxford.

Ladd KL (2016) The study of prayer: Introduction to the special section. In: Village A and Hood Jr RW (eds). Research in the Social Scientific Study of Religion. Brill: Leiden, the Netherlands, pp 109-110.

Larson R and Csikszentmihalyi M (1983) The experience sampling method. New Directions for Methodology of Social and Behavioral Science; 15, 41-56.

Luhrmann T (2012) When God Talks Back: Understanding the American Evangelical Relationship with God. Alfred E. Knopf: New York.

Marr D (1982) Vision: A Computational Investigation in the Human Representation and Processing of Visual Information. Freeman: New York.

Martin C and McCutcheon R (eds) (2012) Religious Experience: A Reader. Equinox: Sheffield/Bristol, UK.

Meyer B, Morgan D, Paine C and Plate SB (2010) The origin and mission of material religion. Religion; 40 (3): 207-211.

Porter M (2017) Contemporary Worship Music and Everyday Musical Lives. Routledge: New York.

Sharf E (1998) Experience. In: Taylor MC (ed). Critical Terms for Religious Studies. University of Chicago Press: Chicago, IL, pp 94-116.

Spilka B and Ladd KL (2012) The Psychology of Prayer: A Scientific Approach. Guilford Press: New York.

\section{Additional information}

Competing interests: The author declares that there are no competing interests.

Reprints and permission information is available at http://www.palgrave-journals.com/ pal/authors/rights_and_permissions.html

How to cite this article: Barrett NF (2017) Ordinary religious experience, learning and adaptation: a call for interdisciplinary inquiry. Palgrave Communications. 3:17061 doi: 10.1057/palcomms.2017.61.

Publisher's note: Springer Nature remains neutral with regard to jurisdictional claims in published maps and institutional affiliations.

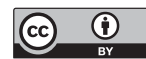

This work is licensed under a Creative Commons Attribution 4.0 International License. The images or other third party material in this article are included in the article's Creative Commons license, unless indicated otherwise in the credit line; if the material is not included under the Creative Commons license, users will need to obtain permission from the license holder to reproduce the material. To view a copy of this license, visit http://creativecommons.org/licenses/by/4.0/

(C) The Author(s) 2017 